\title{
Impact of Non -Tax Revenue on Revenue Expenditure in Sub National Public Finance in Economic Sector
}

\author{
Dr.AsitRanjan Mohanty ${ }^{1}$ Dr.Suresh Kumar Patra ${ }^{2}$ \\ ${ }^{I}$ Professor in Finance, Xavier University and Chair Professor, Centre of Excellence in Fiscal Policy and \\ Taxation (CEFT)Bhubaneswar, ODISHAINDIA \\ ${ }^{2}$ Research AssociateCentre of Excellence in Fiscal Policy and Taxation (CEFT)Xavier Institute of \\ ManagementXavier UniversityBhubaneswar, ODISHAINDIA (Corresponding Author)
}

\begin{abstract}
The most challenging task for a sub-national government is to augment its resources through both tax and non-tax revenue for financing non-plan revenue expenditure. Our analysis is limited only to economic sector as it generates less externality as compared to social and general services sector. We have examined the effect of per capita non-tax revenue on the per capita revenue expenditure in economic service sector in case of 15 NSC sub-national governments of India for the period 2010-11 to 2014-15. The result reveals that the per capita non-tax revenue has favourable effect on per capita revenue expenditure of the sub- national governments. However, the estimated coefficient is inelastic which implies the collection efficiency of revenue sector needs to be further upgraded. As regards to policy implication, government should raise the non-tax revenue through the marginal pricing provision of goods to increase users' coverage.
\end{abstract}

JEL classification numbers: $\mathrm{H} 2, \mathrm{H} 5, \mathrm{O}, \mathrm{C} 33$

Keywords: Non-tax Revenue, Revenue Expenditure, Economic Growth, Fixed Effect

\section{Introduction}

The mostchallenging task for a sub- national government is to augment its untied resources through both tax and non-tax revenuefor to financeexpenditureboth through revenue and capital expenditure. This, in turn, will expedite economic growth through the multiplier effect of the government expenditure and development through the redistributive policy.Though tax revenue is a major component of the own tax revenue of sub- national government, however, mobilizing resources through non-tax sources serves the twin purpose of having a rational non-tax structure and generating resources to finance more expenditure.The importance of non-tax revenue is now being realized by the sub- national governments in India in the context of revenue deficits and, the heavy financial requirements for upgrading and modernizing basic infrastructure (Mohanty, 2014). Therefore, non-tax revenue is essential to finance the repair, maintenance and operations (MRO) of existing capital assets that creates positive externalities as well revenue for the governments. The expenses on account of MRO of capital assets are booked as revenue expenditure. The revenue expenditure may be non-plan and plan expenditure. The Non Plan revenue expenditure essentially includes all committed expenditures such as salary, pension and interest payments. These non-plan expenditures have first charge on the untied own revenue resources of the sub- national governments. The Non-Plan Revenue Expenditure as a proportion of Revenue expenditure constitutes $69.68 \%$ in $2012-13,67.10 \%$ in $2013-14$ and $63.80 \%$ in $2014-15$ and $48 \%$ in 2015-16 of the total Revenue expenditure respectively at all sub-national government levelthe non-plan revenue expenditure in most of the sub- national governments has a major contribution in overall revenue expenditure.

The Plan Revenue expenditure of the state has improved due to increased allocation towards the developmental expenditure in Social Sector and economic sector such as General Education, Medical \& Public Health, agriculture \& allied activities, irrigation, road \& bridges has been increased substantially in the post FRBM period due to generation of revenue surplus (at least zero revenue deficits). Therefore, recently, the emphasis has been laid on maintenance of capital assets in social and economic infrastructure so that both part of revenue receipts and capital receipts would be conserved for creating new capital assets instead of creating similar capital assets. Another reason for the emphasis on the maintenance of existing capital assets is to derive more net present value(NPV) over its life time so that return on capital employed will be maximized.

During 2011-12 to 2015-16, the aggregate share of revenue expenditure to total expenditure is calculated at $80 \%$ for the sub-national governments in India. Therefore, plan revenue expenditure in general and non-plan revenue expenditure in particularare two critical elements in the overall outlay of the sub- national governments.

Both plan and non-plan revenue expenditure in social and general services sector create externalities, whereas in the most of the cases, revenue expenditure in economic services sectors providesdirect benefit to the users. The revenue expenditure constitutes around $35 \%$ of total revenue expenditures whereas the average non tax revenue from this sector has a share of 58\% during 2011-12 to 2015-16 among these three sectorsIf, the 
revenue expenditure in economic services sectors is financed by non-tax revenue generated from that particular sector to take care of MRO by charging user fee, then therest of the untied resources such as tax revenue, shared tax from the centre, both debt and non-debt capita receipts can not only fund other plan and non-plan revenue expenditure. Importantly, it will be helpful to allocate more capital outlay in different sectors. Therefore, nontax revenue over revenue expenditure in the economic sector represents the efficiency.The non-tax revenue has two steps hierarchy such as minor sectors which are mapped to a particular sub sector and the sub sectors are mapped to economic services sector. This efficiency differs from sub-sector to sub sector within the overall economic sector.Higherthe efficiency both at sector and sub-sector level, higher will be the non- tax revenue to meet the expenses on account of revenue sector in Economic services sector.

The current contribution of own non-tax revenues in sub- national government in its own revenue is only about $28 \%$ receipts and the rest is contributed by the tax revenue during 2011-12 to 2014-15. Therefore, there is an urgent need to optimize and enhance the non- tax revenue. This is very crucial from the following points.

a) Since tax revenues are sensitive to growth rate of the economy, the tax revenue drastically falls during the down turn of the economic growth of the sub- national governments. In these circumstances, non-tax revenue gives back up to the revenue receipts of the sub- national governments.

b) Since, FRBM Act stipulates minimum zero revenue deficit,augmentation and accumulation of non-tax revenue will help the sub- national governments to achieve the FRBM mandate.

c) Augmentation of non-tax revenue will give additional cushion to the sub- national governments to fund higher capital outlay when they are in surplus in revenue account.

It is, therefore, appropriate and logical to pay more attention to raise non-tax revenues. This is imperativegiven the widening revenue expenditure gaps in the States' budgeting and the growing public resentmentagainst attempts to raise more revenue through taxation. The discussion on non-tax revenue assumes significance for the economic services sectors as revenue can be generated immediately from the users who get direct benefit as against the non-tax revenue measures in social and general services sectors as it creates huge positive externalities and cannot be measured by monetary measures.

\section{Limitation of the study}

The limitation of this study is to analyse and to evaluate non-tax revenue and corresponding revenue expenditure in economic services sector only and others services create positive externalities for the economy for which expenses on account of revenue expenditure cannot be covered by non-tax revenue. Therefore, efficiency measurement is applicable only to economic services sectors.

In economic services sector as compared to social \& general services sector, the non-tax revenue is generated through user charges(fees) for providing public services. Hence, there is a need to broad-base the nontax revenue in economic services which will bring in buoyancy in non-tax revenue. The non-tax resources, is defined as payment made to the Government for which there is a quid pro quo.

The structural reforms in tax administration in the both in national and sub- national governments targets to reduce the quantum of subsidy and to meet the cost of public services through proper pricing, depending on its feasibility.As free of user charges of public services should be removed and the user charges should be fixed according to both the economic status of the user and the nature or type of the commodity. This should be such that the cost coverage ratio will be optimized and the market price of the commodity does not lead to either over-consumption of such services or wasteful use of scarce resources. This is basically applicable to economic services sector.

\section{Taxonomy of Non-Tax Resources in economic Services Sector and Pricing of Services}

The non-tax revenue from economic services comprise receipts from (a) Crop husbandry, (b) animal husbandry, (c) Fisheries, (d) Forestry and wild life, (e) Co-operation, (f) Other agricultural and rural programmes, (g) Major and medium irrigation, (h) Minor irrigation, (i) Village and small scale industries, (j) Industries, (k) Plantations, (l) Power, (m) Petroleum, (n) Ports and Light Houses, (o) Road Transport, (p) Tourism and, (q) Others.

Under forestry, revenue is mainly realized from forests on Government lands. Forest produce is directly exploited and sold by the Government. Revenue from different items from forests by Government is derived principally from timber, followed by firewood and charcoal, eucalyptus, driftwood, bamboo, sandalwood, grass and sandal oil. Government exercises aregulatory function by levying fines for violations of rules on both Government and privateland and collecting permit and license fees.

Irrigation projects are important national assets, created by pumping in huge investments, whose benefits cannot be evaluated in terms of direct financial returns. They generate social benefits in the form of better health and hygienic standards, better habitats etc., culminating in overall better standards of life, particularly in neglected rural communities, leading to higher productivity of water and land and human 
resources. Based on the area irrigated, these irrigation projects have been classified by the Central Government as major, medium and minor. Those with culturable command area (CCA) above 10,000 hectares are treated as major irrigation projects, those with CCA between 2,000 hectares and 10,000 hectares are treated as medium irrigation projects and others are classified as minor irrigation projects.

Mines and Minerals: Royalty is an important source of non-tax revenue to the mineral producing Subnational governments. However, if the rates of royalty remain unchanged for a long time, the real value of royalty declines significantly due to rising inflation and the Sub- national governments lose considerably. Thus, it is recommended that royalty rates should be increased with due interval of time. In addition, the royalty rates should be based on sale price system as against on quantity basis.

Roads and Bridges: To improve the maintenance of roads it is recommended that the Government should start a system of electronic toll collection either through microwave technology or through infrared technology. This will be able to solve the problem of congestion due to toll collection. Microwave technology, which is commonly used throughout the world, is based on radio frequency waves, which will provide information to the toll collection plaza about the vehicle. Infrared, used mostly in remote controls, is relatively a new technology for toll collection. By using this technology, the processing of toll collection can be completed within a fraction of second.The trends in revenue from non-tax sources clearly bring out the need to improve the growth of non-tax revenues

A major part of non-tax revenue is raised through the collection of user charges, which are administratively determined for the goods and services provided by the sub-national governments. The Governments intervention in the provision of these "public" goods and services is justified on the grounds of imperfect market conditions that prevail in the supply of these goods and services. The marginal cost pricing principle, which is generally applicable for pricing of "private" goods, and services is most relevant way of pricing public goods in economic services sector as marginal cost pricing requires that there should be no externalities in consumption and production, and also presumes competitive forces operate throughout the economy. These completive processes have become intensive because of participation of private players in economic sector through public private sector route or through management contract model. However, there is problem in marginal cost pricing because of lack of data accurate information. However, out of the available pricing models, marginal cost pricing model is the best suited model to price the public goods and services in the economic services sector.

Marginal cost pricing in the economic services sector assumes significance as it has the characteristics of non-excludability where consumption of one user will not exclude the user who does not have paying capacity. It also takes care of joint consumption the consumption of one user will not affect the benefits derived by other users. The benefits of using public goods and services will not create any mutual conflict.

The requisite of marginal cost pricing is minimal external effects in using public goods andservices and competitive forces should operate throughout the economy. Therefore, in economic services sector, marginal cost pricing is the best available option.

\section{Scheme of Presentation}

The relevant literatures are discussed in section 5. Sources of Data and some stylized facts are represented in section 6 . Section 7 deals with the motivation and scope of the study. The objective of the study is discussed in section 8. The methodology is described in section 9. The results and analysis is presented in section 10. The summary, conclusions and policy imperatives are given in section 111.

\section{Relevant Literatures}

Some of the studies on non-tax revenue in public finance literature include Upender (2008), Kaur and Gursimran (2010), Bagchi (1992), Kaur (2003), Mawia and Nzomoi (2013), Mohanty (2014). Upender (2008) estimated tax buoyancy for the country. Bagchi (1992) pointed out that non tax revenue has accounted for a small and declining share of total revenue in India. The Expert Committee on revenue enhancement measures (Hota Committee, 2010) was constituted bythe Government of Orissa. This committee had attempted to measure the potential non tax revenue in Odisha and gap in respect of actual collection. This committee's report is very important from policy prescription point of view. They have identified that the growth of non-tax revenue is very uneven. It is mainly due to wide variations in receipt from sources like Interest, Dividend, and receipts from Forest and Irrigation sectors. Buoyancy is a summary measure of the revenue performance of a State vis-àvis the growth in economy. The committee has identified that in the sub- national governments buoyancy is not seen in non-tax items. Collection from Forest and Wild Life shows most erratic behaviour among the non-tax items mainly on account of seasonal effect.They have opined, "Administration of non-tax revenue sources often determine the actual impact more than the design and structure - so much so that it has been said: tax 
administration is tax policy"They have identified that there is no correlation between higher revenue expenditure on forest conservation and development and the non-tax revenue realized.

Purohit(2006) has supported marginal cost pricing as in general (a) the marginal benefit to the society exceeds themarginal cost, and (b) the marginal benefits of financing the service is at least equal to the possible marginal benefits from other competing public good and services. According to him, the marginal cost theory requires that there the external effects should be minimal in consumption and production, andthere should be participation of competitive forces in providing the same goods and services. In this study, economic services sector is specifically chosen to link with its non-tax revenue ad it has minimal externalities and private sector participation happens through public private sector mode, management contract, build own operate and transfer models. Purohit has further argued that at present, the 'user' charges for the services provided by the Government are negligible or non-existent. Hence, it is generally believed that the user charges must be augmented to reduce the burgeoning Government subsidies and reducing revenue deficits. The Government provides a variety of heterogeneous services. In his opinion, in the economic services sector, all of the sub sectors or minor sectors are not amenable to cost recovery. While some services could have a price recovering the cost incurred, others may be priced just to cover a part of the expenditure incurred in their provision. Also, there are few services for which consumers are not charged at all. The policy to recover expenses should depend upon the type of services provided as there cannot be any universal policy prescription for all the services provided by the Government. However, the marginal cost pricing should be benchmark while pricing these services as it would indicate the financial loss and gain in terms of tax revenue.

Clark (1911) has propounded marginal cost pricing in the utility services. Hotelling(1939) had brought this type of non-tax revenue as part of pricing of public goods and services. In his view, if the market price is determined at a point ofequilibrium of demand (based on marginal utility) and supply (determined by marginal cost), then the governments should price as per marginal cost pricing if the consumers are willing to pay. If the price if consumers were unwilling to pay the cost, then marginal cost pricing may be ignored and cost of provision of services and good may be less than the cost by providing subsidies. The theory of public goods, developed by Samuelson (1954), suggested that the goods consumed by each and every individual in the society, in the same quantity with no exclusion for any individual, have the property of joint consumption or non-rivalarity. In addition, a pure public good exhibits another characteristic called non excludability, i.e. it is not possible to exclude any individual from consuming the good irrespective of his non-payment. Such goods and services, called 'pure' public goods, have to be financed through taxes. The goods and services provided through economic services sector falls in this category. He has further argued that Quasi-public goods, (i.e. merit goods having one of the features of pure public goods) could be subsidised or regulated by the Government through the pricing mechanism. If these goods are provided by the market, they may be underconsumed because individuals typically consider the gains or benefits at the micro/individual level; they do not consider the benefits generated at the macro level for others in society. Both general services and social services sectors are part of theses quasi-public goods. In his opinion, in both services and general sector, consumers do not internalize the positive externalities of the consumption of the goods. Such goods, which include education, preventive healthcare etc., are important examples of producing positive externality. Such merit goods are a good case for imposition of user charges but the structure of the charges must be designed keeping in view the essentiality and externalities of these goods. He further viewed that the primary economic reason for the levy of user charges on the direct recipients of public services is to ensure optimal and efficient use of available resources. This is important when the general fund for financing is scarce. The objective is to recover costs and at the same time, to improve efficiency with which Government uses its resources. Also, it is one of the important elements of financing the increasing demand for these services in the long run.

The view of Samuelson is quite relevant for sub-national governments in India when both tax revenue and grants from the Union government has shown a declining trend in recent years because of sub optimal economic growth (below 8\%) and removal of grants on account of the recommendation of fourteenth finance commission. Clark has further initiated the discussion in favour of Marginal Cost Pricing based upon the premises of justice and equity, wherein, each group of consumers should pay the costs without crosssubsidization. He does not consider the issue of pricing policy against the background of income distribution. Besides, the second principle relates to efficiency in resource allocation. He gives a clear, intuitive explanation of the willingness to pay for incremental output with costs leads to efficient use of productive capacity.

Saleth and Dinar propounded their price theory in the context of water pricing. They argued that economic pricing of water is necessary not only for improving the financial viability and efficiency in water use but also for providing incentive for private initiatives who are given with management contracts after the completion of capital assets, especially in the form of inter-household and inter-sectoral water exchanges and joint ownership and management of ground water wells and other water supply sources by user groups. Their results reveal that under the existing price structure, characterized by increasing intervals between successive 
consumption slabs and slab-specific constant water rates, the water consumption decision is not affected by the Marginal Cost pricing but only by the AC pricing.

It is clear from the foregoing discussions that to recover revenue expenditure pricing of public goods and services is very important albeit the pricing structures are different. This clearly established the fact that non tax revenue should be generated to finance the scare resources of the governments. Anand and Jha(2004) discusses the estimates of the annualised budgetary cost of and recovery from four public services in economic sector, namely, drinking water, irrigation, power and road transport in Rajasthan between 1990-91 and 2006-07. An aggregate under-recovery in these (four) public services, as a proportion of gross state domestic product and very low recovery in drinking water and road transport. They have identified thatthe cost-based pricing for public services in terms of nontax revenue (in the form of user charges) is yet to pick up to recover the corresponding revenue expenditure in the economic sector.

Additionally, the loss on account of provisioning of any particular public good/service through non tax revenue may be compensated or financed, to a certain degree, by funds from untied sources like own taxation. In particular, revenues from sector-specific taxes could possibly be interpreted as recoveries for providing these service. Alternatively, current (accounting) losses on account of less non tax revenue as compared to revenue expenditure may be financed by borrowing, in which case some costs are passed on to next generation and add to the fiscal deficit. They have identified the level of under recoveries of revenue expenditure through non tax revenue. They have argued that Recovery rate may be improved by increasing non tax revenue rate or by reducing revenue expenditure or improving revenue non tax revenue collection by increasing the coverage ratio of the users.

Dholakia (1998) had considered the fiscal instrument of the non-tax revenue (NTR) of the sub-national governments in relation to only those aspects and instruments over which the sub-national governments has sufficient control and it can, if it so desires, try to achieve the constrained maxima in terms of reduction of revenue deficit as well as fiscal deficit through them. Das-Gupta(1990) had argued for leasing contract to provide public good and services in order to maximise non tax revenue in the economic sector. Das (2011) has emphasised the tax collection efficiency from the revenue expenditure in the economic sector as "demand" for on revenues and efficiency in collecting revenue - which, in the literature, has been called "collection efficiency." have cause-effect relationship. It implies that reducing efficiency loss in other sub and minor sectors in economic services. Therefore, tax efficiency is an important parameter to optimise non tax revenue in economic services sector of sub-national governments.Dutta(2015) based on secondary data, an attempted to analyse revenue mobilization efforts of the Government of Assam during 1991-2010. By examining the issues of arrears of uncollected both tax and non-tax revenue, high cost of collection of different taxes and non-taxes and collection efficiency cost low-revenue efforts on the part of the state government.

The studies made by made by Anisworth (1984), Bierhanzl (1999), Fraser and KingwelI(1997), Purohit (1999) and Kaur (2003)though have highlighted the role of non-tax revenue. However, they have not empirically examined the non-tax revenueon revenue expenditure in the economic sectors in order to provide public good. As per the study by Mohanty (2014), capital productivity and tax collection efficiency are the two important sustainability parameters so as to achieve high growth while adhering to FRBM (Amendment) Act, 2011. However, in the literature, no study has attempted to measure the efficiency of revenue expenditure and the relationship between revenue expenditure and non-tax revenuefor sub-national governmentsin India, as per the best of our knowledge. Hence, the analysis of measuring the efficiency of revenue expenditure will be very relevant from policy prospective.

\section{Sources of Data and Some Stylised Facts}

The data for the analysis are sourced from RBI and EPW Research Foundation database. For some of the states such as Odisha, data is sourced from Finance Accounts. On the basis of the average per capita income from 2011-12 to 2015-16, we selected three categories sub- national governments into low income, middle income and high income categories. These slabs are with their per capita GSDP is given below:

The collection efficiency or the coverage ratio is defined as the non-tax revenue generated from the revenue expenditure in the economic services sector. It is estimated for these categories of sub-national governments. The average coverage ratio or the collection efficiency during 2011-12 to 2014-15 is the highest for low income sub-national governments at $57 \%$ followed by high income sub-national governments at $32 \%$. The lowest is for middle income states at $18 \%$. The all India average collection ratio is calculated at only $18.38 \%$. The chart I depicts the collection efficiency at low income, middle income, high income states and at national level. 
Table 1: Per Capita GSDP of Sub national governments

\begin{tabular}{|c|c|c|c|}
\hline \multicolumn{4}{|c|}{ Average Per Capita GSDP(In Rs.)During FY 2004-05 to FY 2014-15 } \\
\hline Sl. No & Sub- national government & Per Capita GSDP & Category \\
\hline 1 & GOA & 166776.6 & \multirow{5}{*}{ High Income } \\
\hline 2 & HARYANA & 86865.5 & \\
\hline 3 & MAHARASHTRA & 79409.7 & \\
\hline 4 & GUJARAT & 75536.6 & \\
\hline 5 & TAMIL NADU & 72617.8 & \\
\hline 6 & KERALA & 70346 & \multirow[b]{4}{*}{ Middle Income } \\
\hline 7 & PUNJAB & 67714.1 & \\
\hline 8 & KARNATAKA & 59660.9 & \\
\hline 9 & ANDHRA PRADESH & 55738.4 & \\
\hline 10 & WEST BENGAL & 45529.9 & \\
\hline 11 & RAJASTHAN & 42882.9 & \multirow{5}{*}{ Low Income } \\
\hline 12 & ODISHA & 39753.1 & \\
\hline 13 & MADHYA PRADESH & 32740.2 & \\
\hline 14 & UTTAR PRADESH & 26187.3 & \\
\hline 15 & BIHAR & 18226.1 & \\
\hline
\end{tabular}

Chart I: Average Collection Efficiency of Non Tax Revenue during 2011-12 to 2014-15

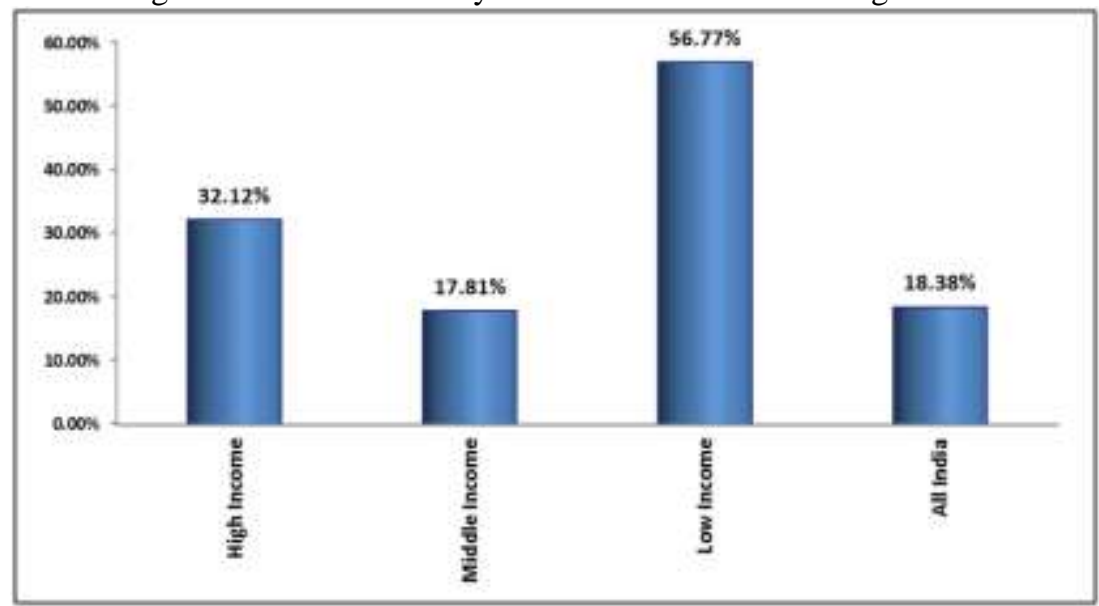

Table II: Estimation of Collection Efficiency during 2011-12 to 2014-15

\begin{tabular}{|l|l|l|l|}
\hline & & & (In Rs. Lakh) \\
\hline Category & $\begin{array}{l}\text { Non } \\
\text { Revenue } \\
\text { (In Rs) }\end{array}$ & $\begin{array}{l}\text { Tax } \\
\text { Expenditure } \\
\text { (In Rs.) }\end{array}$ & $\begin{array}{l}\text { Collection } \\
\text { Efficiency }\end{array}$ \\
\hline High Income & $\mathbf{1 5 4 0 1 4 2}$ & $\mathbf{4 7 9 4 3 3 8}$ & $\mathbf{3 2 . 1 2 \%}$ \\
\hline Middle Income & $\mathbf{7 9 6 6 8 1}$ & $\mathbf{4 4 7 3 9 5 1}$ & $\mathbf{1 7 . 8 1 \%}$ \\
\hline Low Income & $\mathbf{2 2 0 9 0 2 6}$ & $\mathbf{3 8 9 0 9 6 4}$ & $\mathbf{5 6 . 7 7 \%}$ \\
\hline All India Average & $\mathbf{6 6 6 6 5 2 9}$ & $\mathbf{3 6 2 7 1 4 2 1}$ & $\mathbf{1 8 . 3 8 \%}$ \\
\hline
\end{tabular}

In low income sub national governments, the non-tax revenue collection is the highest. It is $177 \%$ higher than middle income sub national governments and $43 \%$ higher than high income sub national governments. In terms of low income sub national governments revenue expenditure in economic services sector, low income sub national governments has 13\% lower revenue expenditure as compared to middle income sub national governments and 19\% lower than high income sub national governments. Since, the low income sub national governments are recovering more from less revenue expenditure, the collection efficiency is highest. The probable reasons could be as the high and middle income brackets are spending more on revenue expenditure in economic services sector, the coverage ratio could be low and therefore, the relative collection efficiency is low.

It is emerged from the analysis that high income may not lead to higher coverage ratio. The reasons may be: a) the pricing structure of public goods and services, b) the high income group may think they are exempted from user fee, c) the coverage ratio i.e. the user covered to collect non tax revenue may not be adequate in both high and low income sub national governments, d) the untied tax revenue are very high that least importance is given in high and low in come sub national governments. 
We have investigated the collection efficiency/ coverage ratio in the Economic Sector by taking sample from high, middle and low income sub national governments. Tamil Nadu from high income, Andhra Pradesh from middle income and Odisha from low income sub national governments are selected. The collection efficiency at minor sector, sub sector and major sector was estimated for the period FY 2011-12 to FY 201415.The average collection efficiency in the over-all Economic Sector is the highest in Odisha followed by Andhra Pradesh and Tamil Nadu. This result corroborates our earlier findings at group level.

Table III: Average collection efficiency for Selected Indian Sub- national governments(2011-12 to 2014-15)

\begin{tabular}{|l|l|l|l|}
\hline Sectors & Odisha & AP & Tamil Nadu \\
\hline CRPHUS & $0.44 \%$ & $0.50 \%$ & $5.21 \%$ \\
\hline FISH & $0.39 \%$ & $0.47 \%$ & $1.54 \%$ \\
\hline FWILD & $2.18 \%$ & $4.45 \%$ & $3.56 \%$ \\
\hline COOP & $32.55 \%$ & $40.79 \%$ & $40.59 \%$ \\
\hline OAGRPR Allied & $0.93 \%$ & $12.94 \%$ & $3.67 \%$ \\
\hline $\begin{array}{l}\text { Total Agriculture and } \\
\text { Activities }\end{array}$ & $33.27 \%$ & $0.29 \%$ & $28.09 \%$ \\
\hline MAMIR Economic Services & $52.82 \%$ & $4.77 \%$ & $7.21 \%$ \\
\hline $\begin{array}{l}\text { Aggregate } \\
\text { Sector }\end{array}$ & $63.97 \%$ & $2.42 \%$ & $3.92 \%$ \\
\hline
\end{tabular}

1.CRPHUS: Crop Husbandry, 2. ANIHUS: Animal Husbandry, 3. FISH: Fisheries,4. FWILD: Forestry and Wild life, 5. COOP: Co-operation, 6. OAGRPR: Other Agricultural Program. All these constitute total Agriculture and Allied Activities. 7. MAMIR: Major, medium and minor irrigation

The average collection efficiency in the Economic Sector of Odisha during 2011-12 to 2014-15 has $53 \%$ while it is $15 \%$ and $8 \%$ respectively for AP and Tamil Nadu during the same period. Hence, the collection efficiency is the highest for low income governments followed by middle and high income governments (see Table II).After investigating the state wise collection ratio on sampling basis, we have attempted to estimate the collection efficiency of Odisha against all India average during the same period (see Chart II).

Chart II: Annual Average of collection efficiency of Odisha and All India Average

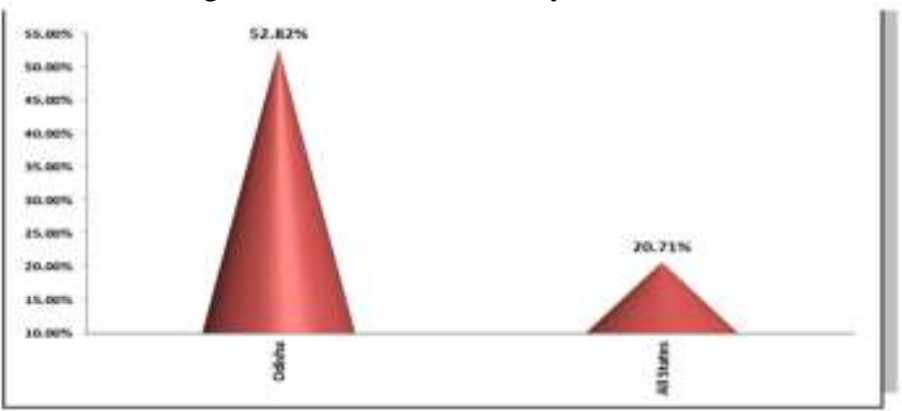

Collection efficiency of Major \& Medium Irrigation Services sector has contributed to the higher collection efficiency. This is very insignificant for Tamil Nadu (3.92\%) and A.P (2.42\%) during 2011-12 to 2014-15. The high water tariff for industrial, commercial and energy sector in 2010. This may have contributed for higher collection efficiency in the major Irrigation sector.

In case of agriculture and allied activities, collection efficiency is highest for Tamil Nadu (7.21\%) followed by Odisha (6.19\%) and A.P (4.77\%) during 2010-11 to 2014-15. In the sub-major heads of Agriculture and Allied Activities, collection efficiency on forest and wild life (FWILD) is highest followed by other agricultural programs (OAPR) in Odisha. The details of the sector wise and year wise collection efficiency for these three state are given in Annexure I.

It is a very important research question why the collection efficiency in low income sub national governments is higher than the middle income and high income sub national governments. The revenue expenditure in both Tamil Nadu and A.P relative to Odisha is quite high as depicted below (Chart III). On an average, the revenue expenditure in Economic Services Sector of Tamil Nadu and A.P is 1.65 times and 2.49 times of the revenue Expenditure in Economic Services Sector of Odisha. 
Chart III: Comparison of Revenue Expenditure Ratio among the Three States

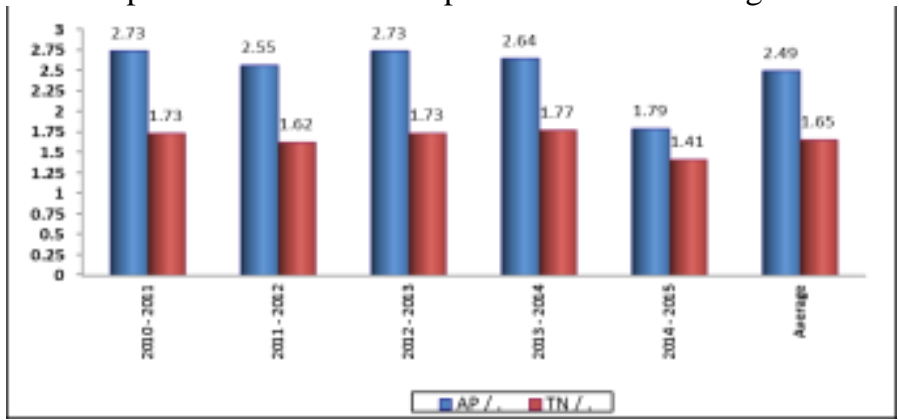

The Non Tax Revenue collection from the economic services sector in Tamil Nadu and A.P realtive to Odisha is very less ( Chart IV). On an average, the non-tax revenue from the economic sector in Tamil Nadu and A.P is 0.26 times and 0.69 times of Odisha.

Chart IV: Comparison of Non Tax Revenue Ratio among the Three States

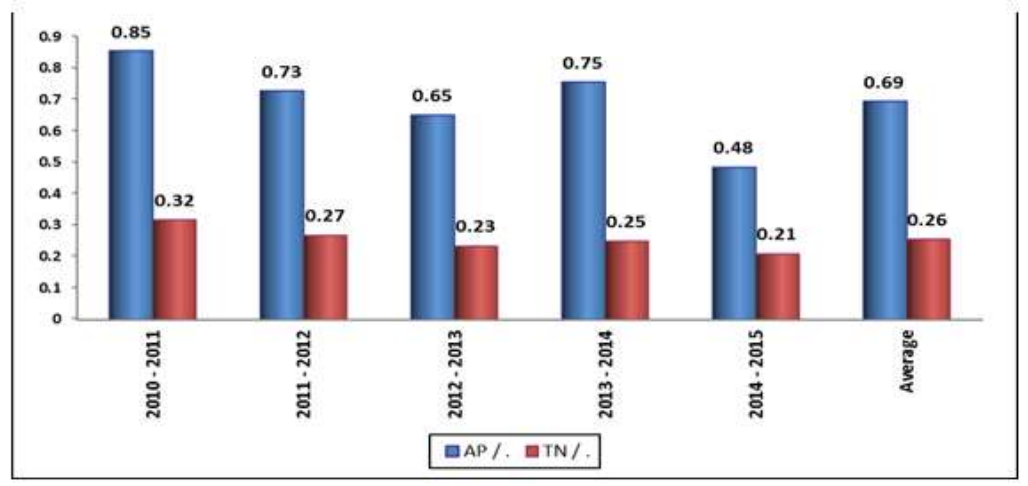

This has motivated us to comare the collecton efficiency of these three category of sub national govenments respective in terms of their untied tax revenue. We have defined untied tax revenue as the state own tax excluding non -tax and shared tax of the Unoin Government as proportion of GSDP. This is also know as tax collection efficiency exclding non tax revenue. These shared tax is part of the horozontal distribution decided by succesive finance commission.

Chart V: Comparison of Collection Efficiency and Tax Efficiency

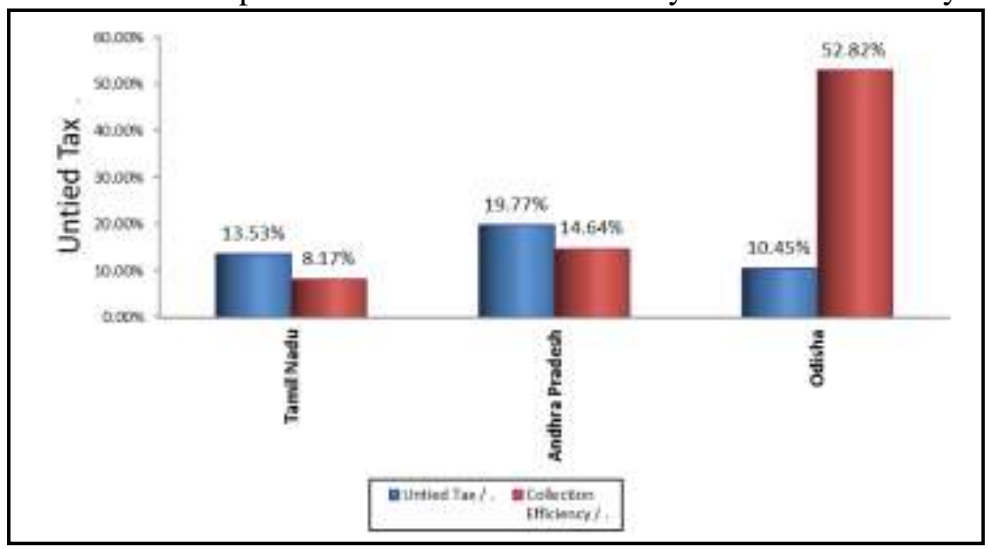

It is very interesting to note that the states with higher collection efficiency in tax and shared tax have lower collection in non-tax revenue. This raises the issue that collection of tax through non-tax does not assume significance when more revenue is generated through untied tax. Therefore, the pricing of products and services in economic sectors is neglected and, usually not determined on economic sense in high income brackets. The correlation coefficient between tax and non-tax collection efficiency is calculated at (-) 66\%. It appears that the collection efficiency in non-tax revenue in our economy is low because of high income sub-national governments. 


\section{Motivation and Scope of the Study}

AtSub- national government levels in India in general and low income brackets in particular, the low collection efficiency in economic sector through non tax revenue, needs attention as the revenue collected can be further used for MRO and paying salary in this particular sector. As a result, the capital assets in the economic sector will continue its productivity with high longevity. As a result, the net present value will be higher. If this happens to all capital assets in economic sector which aregenerally physical capital assets are part of economic sector, then the NPV of this sector will go up and its marginal contribution to GSDP will be enhanced. Thus, the Government needs to aim at enhance cost recovery with higher collection efficiency. This has to be done keeping in mind that the goods provided in the economic sector has less externalities. However, fixation of user charges for non-tax sources is a complex issue. While rational user charges can generate means to achieve a greater growth rate, an irrational structure can cause adverse economic effects which invalidate growth objectives. Hence, resources mobilized through reforms in non-tax sources plays a pivotal role by creating a rational non-tax structure and generating greater means to achieve sustained higher economic growth. Therefore, it is important to keep the objectives of equity, consumer acceptability, administrative feasibility, environmental issues etc. in view while fixing the user charges. Looking at higher collection efficiency in low income bracket and low income efficiency in high income bracket, it has motivated us to examine the impact of collection of no- tax revenue on revenue expenditure in economic sector.

In this backdrop, the present study examinesthe impact of collection from non-tax revenue on revenue expenditure in the economic sector and its implication. This paper attempts to estimate the effect of per capita non-tax revenue collectionon per capita revenue expenditure in economic service sector for 15 non-special category sub- national governments in India for the period 2010-11 to 2014-15.

\section{Objectives of the Study}

Keeping in view the efficiency of non-tax revenue, the present study aims to estimate per capita non tax revenue of the economic sector for all 15 sub national governments for the period 2010-11 to 2014-15. Similarly, per capita revenue expenditure is calculated. In nutshell, this main objective of the study is to undertake a comprehensiveanalysis to measure collection efficiencyof the non- tax revenue in economic services sector both at sector, subsector and minor sector level in economic services sector (Chart 2 to Chart 11) taking the sample sub national governments.Further, the study attempts to analyse the effect of per capita non-tax revenue on per capita revenue expenditure in economic service sector in case of 15 NSC (non-special category) sub- national governments of India for the period 2004-05 to 2014-15 (Annexure II).

\section{Methodology}

Further, we estimated the effect of per capita non-tax revenue on per capita revenue expenditure using fixed effect method using panel regression model.

\subsection{Fixed Effect Model}

Fixed Effect method (FE) establishes the relationship between independent and dependent variables within an entity. Each entity has its own individual characteristics that may or may not influence the predictor variables. While applying fixed effect method, we assume that something within the individual may impact or bias the predictor or outcome variables and we need to control for this. The FE method removes the effect of those time invariant characteristics in the model and we can evaluate the net effect of the predictors on the outcome variables.Another important assumption of the FE model is that those time-invariant characteristics are unique to the individual and should not be correlated with other individual characteristics. Each entity is different therefore the entity's error term and the constant (which captures individual characteristics) should not be correlated with the others. If the error terms are correlated, then FE is not suitable since inferences may not be correct and you need to model that relationship (probably using random-effects), this is the main rationale for the Hausman test. In addition, the fixed-effects model controls for all time-invariant differences between the individuals, so the estimated coefficients of the fixed-effects models cannot be biased because of omitted timeinvariant characteristics. In this analysis, we used the fixed effect method to estimate the influence of per capita non-tax revenue on per capita revenue expenditure controlling per capita capital outlay in the model. The choice between fixed effect and random effect model has been carried out by performing the Hausman test. The Hausman test concluded that random effect estimators are less efficient than fixed effect model.

We estimated the following function using the Fixed Effect panel data technique.

$$
y_{i t}=\alpha_{i}+\beta \chi_{i t}+\varepsilon_{i t}(\mathbf{1})
$$


Where, $\mathrm{y}_{\mathrm{it}}$ is $1 \times 1, \beta$ is a $1 \times \mathrm{k}$ vector of the slope parameters, $\alpha_{\mathrm{i}}$ is the intercept and $\varepsilon_{\mathrm{it}}=$ the stationary regression error.

We can rewrite the $\mathrm{Eq}(1)$ as follows:

$$
P R E_{i t}=\alpha_{i}+\beta P N T R_{i t}+\mu P C O_{i t}+\varepsilon_{i t}
$$

Where, PRE =Per Capita Revenue Expenditure in economic service sector, PNTR = Per Capita Nontax Revenue collection in economic service sector for particular year and for particular sub national governments. PCO $=$ Per Capita Capital Outlay in economic service sector, $\alpha_{\mathrm{i}}=$ Intercept, $\beta$ and $\mu$ are the respective coefficients of Per Capita Non-tax Revenue and Per Capita Capital Outlay and $\varepsilon_{\mathrm{it}}=$ the stationary regression error. Therefore, the entire data set constitutes panel data. Per capita non-tax revenue is not the only variable that affects per capita revenue expenditure rather other variables can also influence the latter. Hence, for the robustness of our results and to avoid the specification bias, we added the control variable i.e. per capita capital outlay in the Eq (2). The entire logic of including the capital outlay as control variable which finance capital assets in a particular year is that new capital assets immediate require revenue expenditure. Since our objective is to examine the non-tax collection and revenue expenditure, we take the capital outlay as control variable to separate the impact of non-tax collection on revenue expenditure for this panel data. Hence, we attempted to analyse the effect of per capita non-tax revenue in economic service sector on the per capita revenue expenditure in that sector for 15 NSC sub- national governments of India for the period 2010-11 to $2014-15$

\section{Fiscal Significance}

This section outlines fiscal significance of Economic Services Sector and Revenue Expenditure.

\subsection{Revenue Expenditure}

An expenditure that neither creates assets nor reduces a liability is categorized as revenue expenditure. Generally, expenditure incurred on normal running of the government departments and MRO of services is treated as revenue expenditure. It is a short period expenditure and recurring in nature which is incurred every year (as against capital expenditure which is long period expenditure and non-recurring in nature). The purpose of such expenditure is not to build up any capital asset, but to ensure normal functioning of government machinery and capital assets.Revenue Expenditure is an amount that is expensed immediately - thereby being matched with revenues of the current accounting period.

\section{Results and Analysis}

The result obtained from fixed effect model is explained in detail in this section.

\subsection{Analysing the Effect of Non-Tax Revenue on Revenue Expenditure}

In this present analysis $\mathrm{F}$ test supported fixed effect specification over the pooled regression specification (Annexure II). Further, to examine whether the fixed effect estimators are more efficient or that of random effects, we performed Hausman test. The Hausman test result supported the fixed effect method for the present analysis (Annexure II). After getting confirmation from Hausman test, we moved ahead to estimate the Eq. (2) using fixed effect method. The results of fixed effect approach are presented in theEq (3).PRE is per capita revenue expenditure, PNTR is per capita non tax revenue expenditure and PCO is per capita outlay.

$\mathrm{PRE}=1375.18 * * *+0.64 * * * \mathrm{PNTR}+0.77 * * * \mathrm{PCO}$

$$
\begin{array}{lll}
\text { P-val. }=(0.00) & (0.00) & (0.00) \\
& \left(\mathrm{R}^{2}=0.82\right)
\end{array}
$$

The fixed effect estimates reveal that both the per capita non-tax revenue and per capita capital outlay are strongly positive and significant at 1 per cent level in the model (also see the Table 5 in Annexure II). The sign of the coefficients of these variables in the model are as per their theoretical expectation. The coefficient of PNTR in the model is 0.64 which implies that Rs. 100 rise in in per capita non-tax revenue in economic services sector, the per capita revenue expenditure in that sector increases by Rs.64. This is controlled by the effect of capital outlay of the same year.

\section{Summary of Conclusions and Policy Imperatives}

Augmenting resources through tax and non-tax revenue to finance expenditure is a challenging task for any sub- national government. Revenue mobilization (including tax and non-tax revenue), in turn, will finance capital outlay to enable higher growth rate. Resources mobilization through non-tax sources helps in financing revenue expenditure for operation and maintenance activities of capital assets. This, in turn, will check the rate of depreciation of capital assets and incremental capital output ratio and consequently net present value of the assets. The importance of non-tax revenue is now being realized by the sub- national governments in India in the 
context of low buoyancy in tax revenue. Besides, limit on revenue deficit, limit on borrowing and consequent interest payments by the FRBM Act.The higher financial requirements in terms of revenue expenditure for upgrading and modernizing basic infrastructure requires non tax revenue so that other unties resources can be used to create new capital assets in accordance with the priority off the sub national governments. Non-tax revenue has been paid due attention in Indian sub- national governments as it can be an important tool to meet revenue deficits and also solves the financial constraints for upgrading and modernizing basic infrastructure. Realizing the importance of non-tax revenue, the present paper attempted to calculate the collection efficiency. Collection efficiency only in Economic Services Sector is taken into consideration as both Social and General Services Sector may not be a proper as these sector have huge externalities.

The study mainly concludes that the collection efficiency is higher in low income sub national governments. It is also obtained from the empirical study thatboth the per capita non-tax revenue and per capita capital outlay have significant and favorable effect on per capita revenue expenditure in the economic service sector. For the policy point of view, it indicates higher revenue collection efficiency will finance higher revenue expenditure so that productivity of the assets will not deteriorate immediately and depreciation will be minimized.Non-tax revenue needs to be taken as a significant source of budgetary receipts for sub national governments in order to enhance the revenue receipts. The impact of non-tax revenue on revenue expenditure is calculated at 0.64 on per capita basis which indicates that $64 \%$ of the non-tax revenue on per capita basis is utilized for revenue expenditure in the economic sector. Therefore, there is gap of $34 \%$ on per capita basisThis gap needs to be reduced and to be spend for the users/consumers to avail incremental facilitates through provision of public goods and services. This in turn, will help to raise the collection efficiency by charging marginal cost. Besides, the depreciation of capital assets will also be reduced by spending more on revenue expenditure which will be financed by non-tax revenue.

As user charges are sometimes perceived as a form of taxation by the users and citizens as they are yet to be convinced as these provisions are linked to specific benefits, which are over and above those enjoyed by the general public.Therefore, the sub national Governments should prioritize by incorporating creating awareness among citizens and users with respect to provision of services and goods in economic sector. From this point of view, what matters is not just to impose charges but to convince and levy the appropriate user fees so that the coverage will go up and collection will be improved.

\section{Reference}

[1]. Ainsworth, M. (1984).User Charges for Cost Recovery in Social Sectors: Current Practices."Country Policy Department Discussion Paper, World Bank, Washington.

[2]. $\quad$ Anand, Mukesh and RaghabendraJha. 2004. "Budgetary Subsidies and Fiscal Deficit:

[3]. Case of Maharashtra", Economic and Political Weekly 39 (August 21): 3827-3834.

[4]. Bagchi, A. (2005). Symposium on Report of Twelfth Finance Commission: Introduction and Overview, Economic and Political Weekly, July 30 - August 5, Pg. 3388-3395.

[5]. Bierhanzl, Edward J. (1999). Incentives for Efficiency: User Charges and Municipal Spending. Journal of Public Finance and Public Choice/EconomiaDelleSceltePubbliche17: 19- 34

[6]. Clark, J.M. 1911. "Rates for Public Utilities". American Economic Review, I, September: 473-87.

[7]. Das-Gupta, A (1990): 'Taxation, Non-Tax Policy and Capital Equipment Leasing, Economic and Political Weekly 25 (May 1990): M88-M90.

[8]. Dholakia, Archana (1998): 'Growth and Structure of Tax and Non-Tax Revenue of Gujarat', Indian Journal of Regional Science, Vol 30, No 1.

[9]. Fraser, Rob, and Ross KingwelI. (1997). Can Expected Tax Revenue be Increased by an Investment Preserving Switch from advalorem Royalties to a Resource Rent Tax?. Resources Policy 23: 103-108.

[10]. Hotelling, H. 1939. "The Relation of Prices to Marginal Cost in an Optimum System". Econometrica.

[11]. 7: 151-5

[12]. Musgrave, Richard A. and Peggy B Musgrave. (1989). Public Finance in Theory and Practice, 5th edition, Boston: McGraw Hill Book Company.

[13]. Kaur, H. (1991). Taxation and Development Finance in India. Published Ph. D. Thesis, Classical Publishing Co., New Delhi, 1991.

[14]. Kaur, H. and Gursimran (2010), Revenue of the Central Government of India: Pre and Post ReformPosition.Journalof Engineering, Science and Management Education, Vol. 3, December. 2010, Pg. 27-32

[15]. Mawia, M. and J. Nzomoi. (2013).An Empirical Investigation of Tax Buoyancy in Kenya. African Journal of Business Management, Vol.7 (40), pp. 4233-4246.

[16]. Mohanty, A. (2014). Effectiveness in Management of Sub- national government Finance: An Empirical Analysis for Odisha. Odisha Review. pp: 31-40.

[17]. Dutta, M.K (2015), "South Asian Journal of Macroeconomics and Public Finance" Vol 4, No 2, PP: 178-204

[18]. Purohit, C.P and Purohit, V.K (2009): 'Mobilising Non-Tax Revenue: An Empirical Analysis of Trends in States', Economic and Political Weekly 44 (January 31): 54-62.

[19]. Saleth, R.M. and A. Dinar. 1997. Satisfying Urban Thirst, Water Supply Augmentation and Pricing

[20]. Policy in Hyderabad City, India. World Bank Technical Paper No. 395. Washington DC: The World

[21]. Bank

[22]. Satya P. Das, (2011),"The political economy of revenue pressure and tax collection efficiency", Indian Growth and Development Review, Vol. 4 Iss 1 pp. $38-52$

[23]. Samuelson, Paul A. 1954. "The Pure Theory of Public Expenditure". Review of Economics and

[24]. Statistics, Vol. 36 (4) Nov.: 387-389. 
Impact of Non-Tax Revenue on Revenue Expenditure in Sub National Public Finance in Economic

[25]. Sharma, R. K. and S.K.Kulshrestha (2015). An Analysis of Non Tax Revenue Buoyancy in India. International Journal of Research in Economics and Social Sciences (IJRESS). $\quad$ vol-5, issue: 7, pp:1-7.

[26]. Upender, M (2008), Degree of Tax Buoyancy in India: An Empirical Study, International Journal of Applied Econometrics and Quantitative Studies, Vol. 5-2, pp. 60-70.

\section{Annexure I}

Table 2: Collection Efficiency in Economic Service Sector (2010-11 to 2014-15)

\begin{tabular}{|l|l|l|l|l|l|l|l|}
\hline Years & $\begin{array}{l}\mathbf{2 0 1 0}- \\
\mathbf{2 0 1 1}\end{array}$ & $\begin{array}{l}\mathbf{2 0 1 1}- \\
\mathbf{2 0 1 2}\end{array}$ & $\begin{array}{l}\mathbf{2 0 1 2}- \\
\mathbf{2 0 1 3}\end{array}$ & $\begin{array}{l}\mathbf{2 0 1 3}- \\
\mathbf{2 0 1 4}\end{array}$ & $\begin{array}{l}\mathbf{2 0 1 4} \\
\mathbf{2 0 1 5}\end{array}$ & $\begin{array}{l}\text { HI:2015- } \\
\mathbf{1 6}\end{array}$ & $\begin{array}{l}\text { Average } \\
\mathbf{1 1} \text { to 2014-15) }\end{array}$ \\
\hline a. Crop Husbandry & $0.97 \%$ & $0.38 \%$ & $0.28 \%$ & $0.32 \%$ & $0.23 \%$ & $0.22 \%$ & $0.44 \%$ \\
\hline b. Animal Husbandry & $0.51 \%$ & $0.38 \%$ & $0.36 \%$ & $0.39 \%$ & $0.32 \%$ & $0.52 \%$ & $0.39 \%$ \\
\hline c. Fisheries & $2.57 \%$ & $2.68 \%$ & $2.75 \%$ & $1.21 \%$ & $1.66 \%$ & $0.73 \%$ & $2.18 \%$ \\
\hline d. Forestry and Wild Life & $45.61 \%$ & $64.60 \%$ & $43.08 \%$ & $4.59 \%$ & $4.88 \%$ & $3.95 \%$ & $32.55 \%$ \\
\hline e. Cooperation & $1.56 \%$ & $0.99 \%$ & $1.06 \%$ & $0.63 \%$ & $0.39 \%$ & $0.40 \%$ & $0.93 \%$ \\
\hline $\begin{array}{l}\text { f. Other Agriculture } \\
\text { Programmes }\end{array}$ & $22.36 \%$ & $55.65 \%$ & $50.85 \%$ & $12.87 \%$ & $24.65 \%$ & $50.00 \%$ & $33.27 \%$ \\
\hline $\begin{array}{l}\text { Total (Agriculture } \\
\text { \& Allied Activities) }\end{array}$ & $10.66 \%$ & $10.34 \%$ & $7.54 \%$ & $1.33 \%$ & $1.07 \%$ & $0.79 \%$ & $6.19 \%$ \\
\hline a. MAMIR & $42.33 \%$ & $73.31 \%$ & $81.48 \%$ & $60.90 \%$ & $61.83 \%$ & $82.80 \%$ & $63.97 \%$ \\
\hline b. MINIR & $3.35 \%$ & $4.14 \%$ & $2.51 \%$ & $1.66 \%$ & $2.30 \%$ & $3.52 \%$ & $2.79 \%$ \\
\hline Total (IRR) & $24.29 \%$ & $49.05 \%$ & $47.77 \%$ & $29.98 \%$ & $36.26 \%$ & $52.49 \%$ & $37.47 \%$ \\
\hline Power & $1.20 \%$ & $19.55 \%$ & $22.51 \%$ & $40.27 \%$ & $21.64 \%$ & $37.68 \%$ & $23.81 \%$ \\
\hline $\begin{array}{l}\text { Villages and Small } \\
\text { Scale Industries }\end{array}$ & $0.35 \%$ & $0.44 \%$ & $0.14 \%$ & $0.26 \%$ & $0.11 \%$ & $0.53 \%$ & $0.26 \%$ \\
\hline Tourism & $1.18 \%$ & $0.78 \%$ & $6.66 \%$ & $0.53 \%$ & $5.85 \%$ & $5.80 \%$ & $3.00 \%$ \\
\hline ROAD & $10.27 \%$ & $6.22 \%$ & $3.84 \%$ & $4.25 \%$ & $3.09 \%$ & $6.21 \%$ & $5.54 \%$ \\
\hline $\begin{array}{l}\text { Aggregate } \\
\text { ServicesSector }\end{array}$ & $52.80 \%$ & $59.83 \%$ & $62.49 \%$ & $50.02 \%$ & $38.94 \%$ & $36.92 \%$ & $44.87 \%$ \\
\hline
\end{tabular}

Chart 2: Collection Efficiency in Economic Sector in case of AP, Odisha and Tamil Nadu

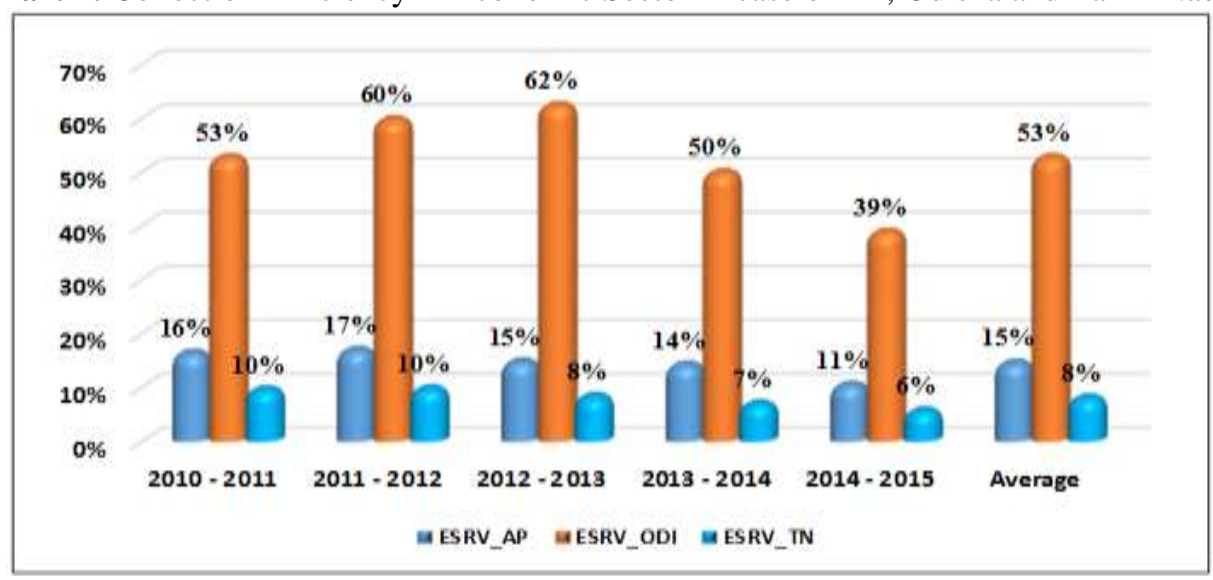

Note: ESRV_AP: Economic Services for Andhra Pradesh; ESRV_ODI: Economic Services for Odisha; ESRV_TN: Economic Services for Tamil Nadu.

Chart 3: Collection Efficiency in Agriculture and Allied Activities in Odisha

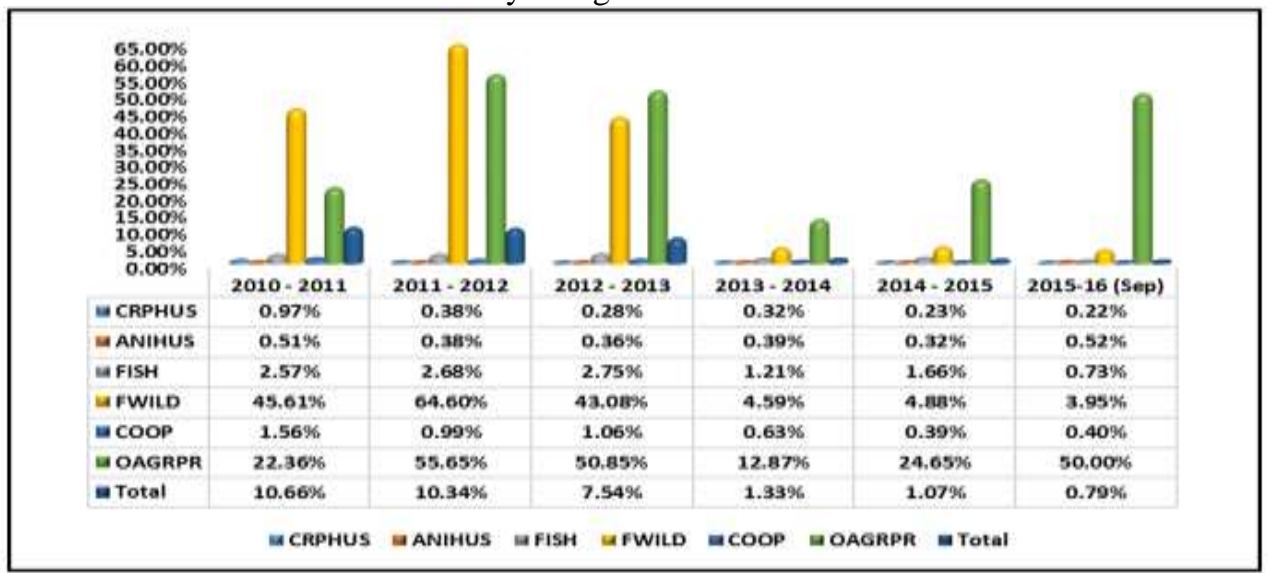

CRPHUS: Crop Husbandry, ANIHUS: Animal Husbandry, FISH: Fisheries, FWILD: Forestry and Wild Life, COOP: Co-operation, OAGRPR: Other Agricultural Programme 
Chart 4: Collection Efficiency for Agriculture and Allied Activities in AP

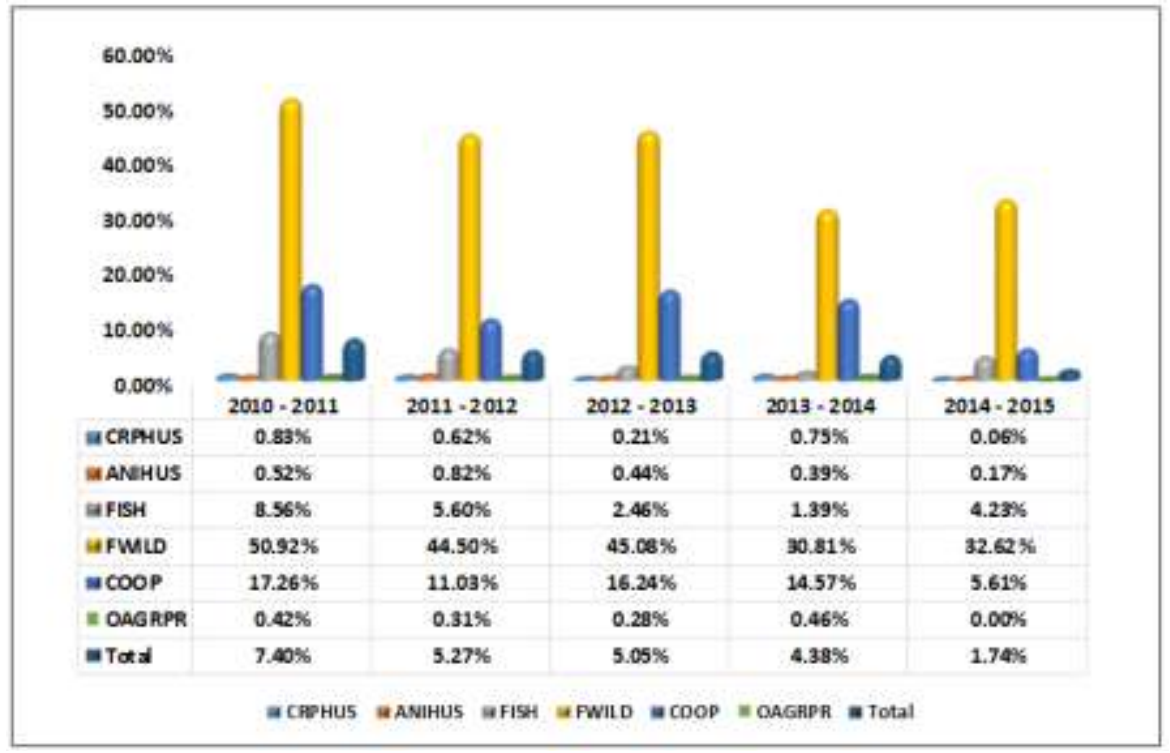

Chart 5:Collection Efficiency for Agriculture and Allied Activities in Tamil Nadu

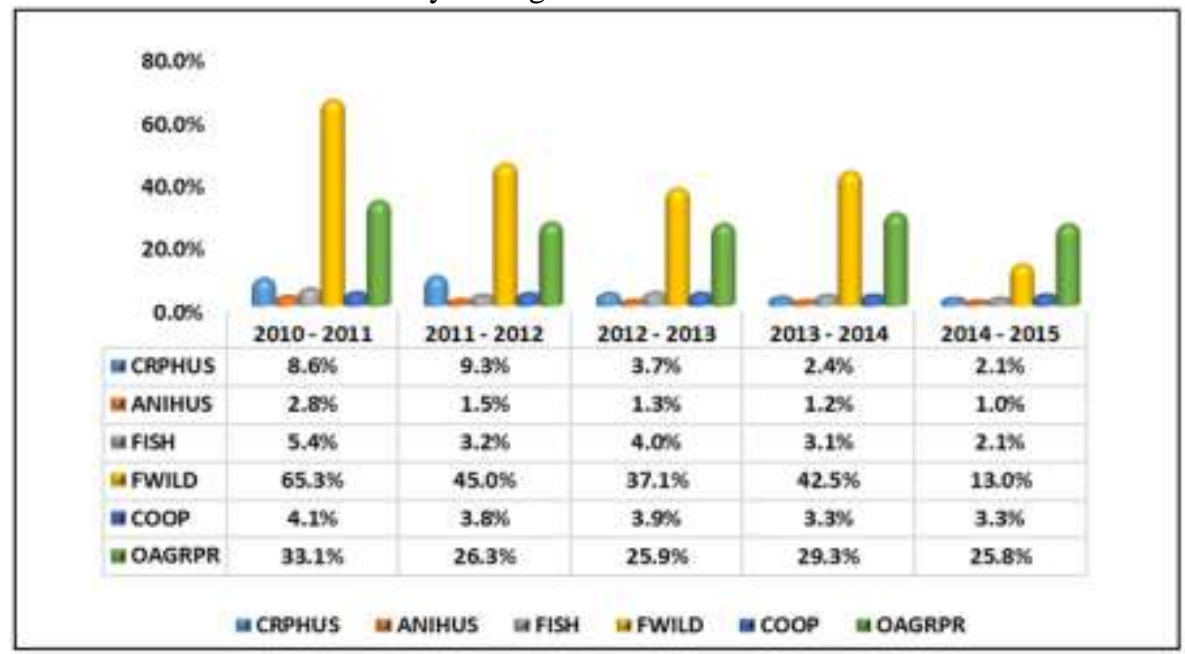

Chart 6: Collection Efficiency for Major and Medium Irrigation in Odisha

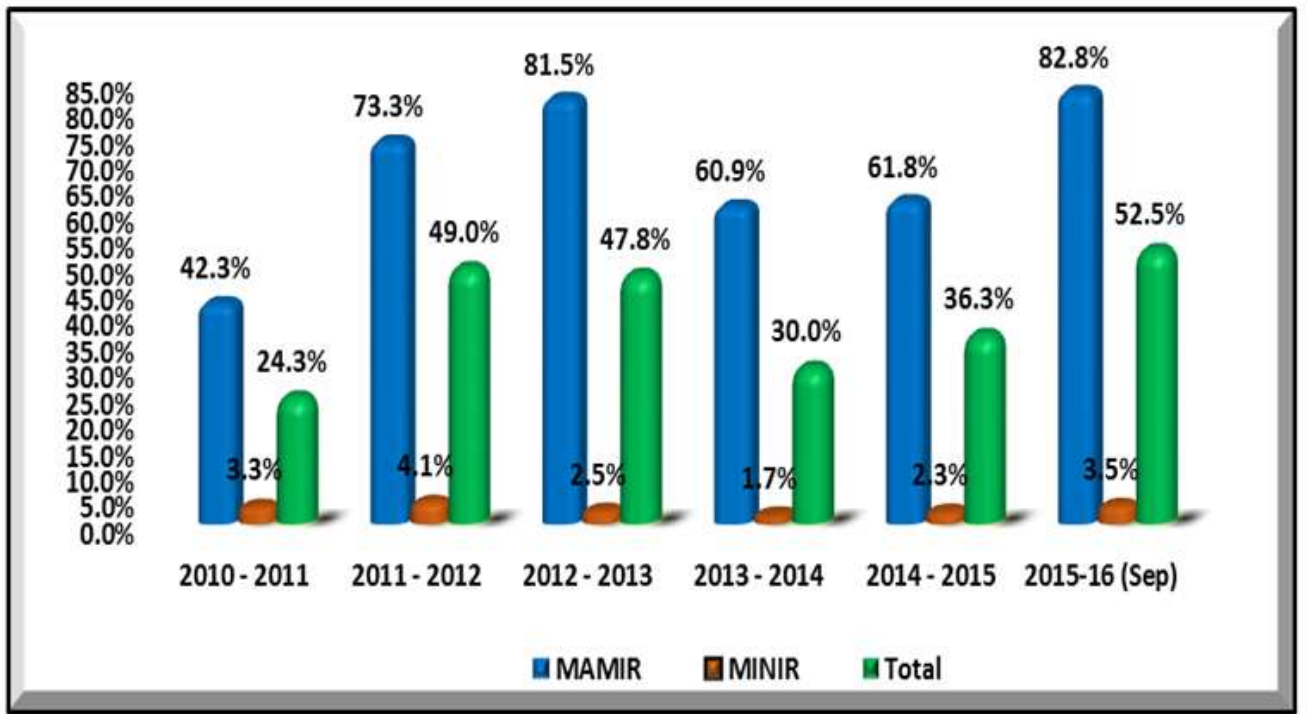

MAMIR: Major and Medium Irrigation, MINIR: Minor Irrigation. 
Chart 7:Collection Efficiency for Major and Medium Irrigation in AP

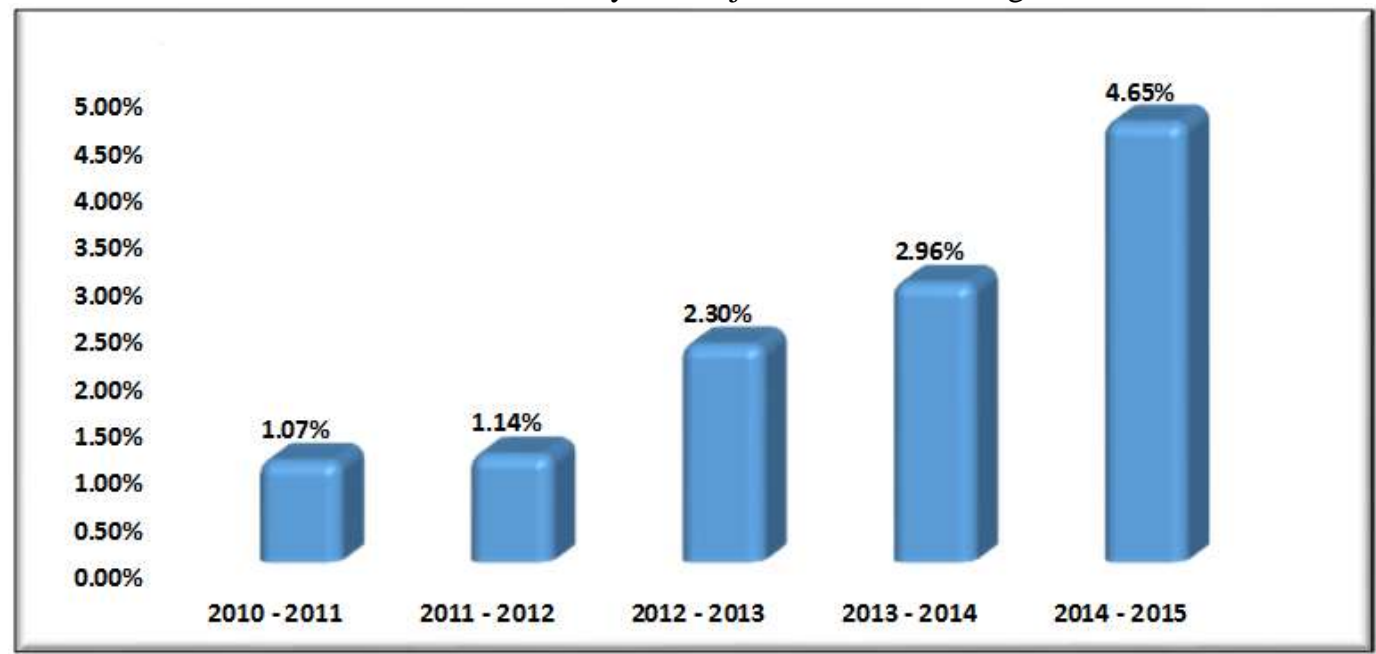

Chart 8:Collection Efficiency for Major and Medium Irrigation in Tamil Nadu

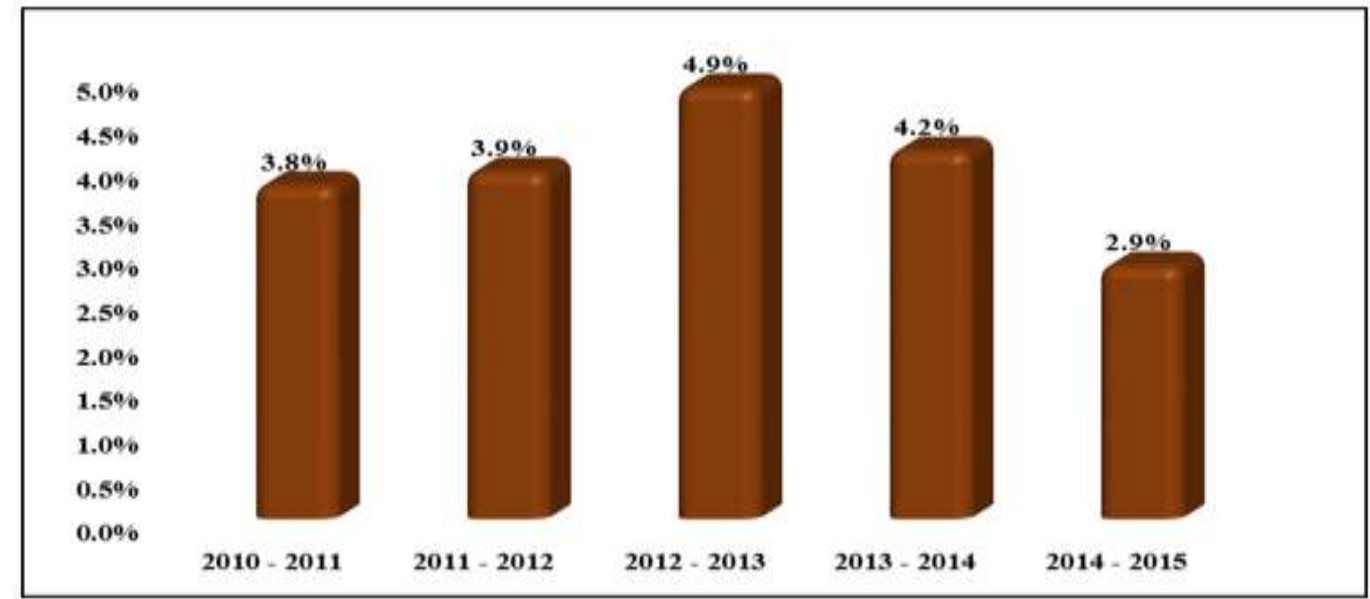

Chart 9: Collection Efficiency in Village and Small Industries in Odisha

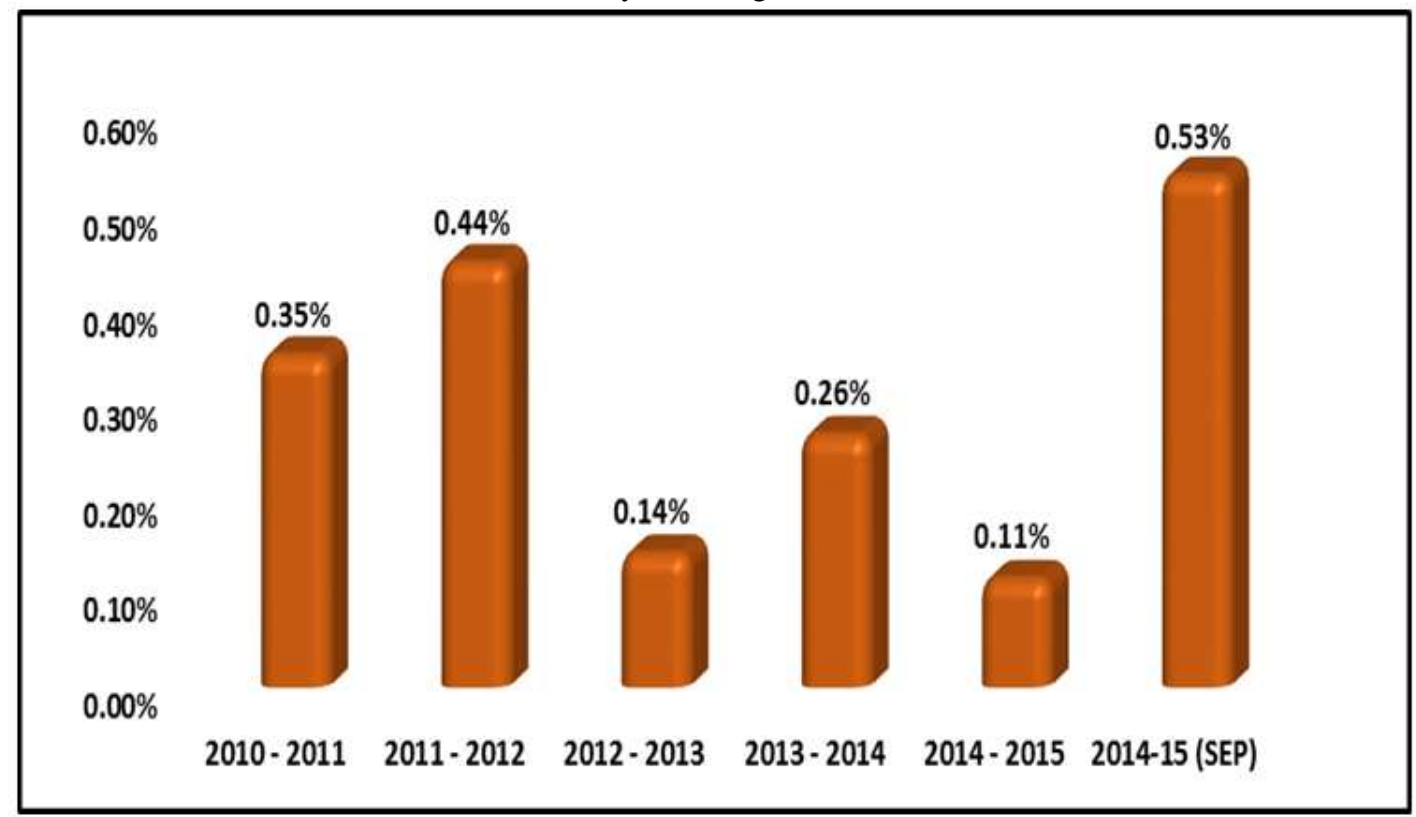


Chart 10: Collection Efficiency in Roads and Bridges

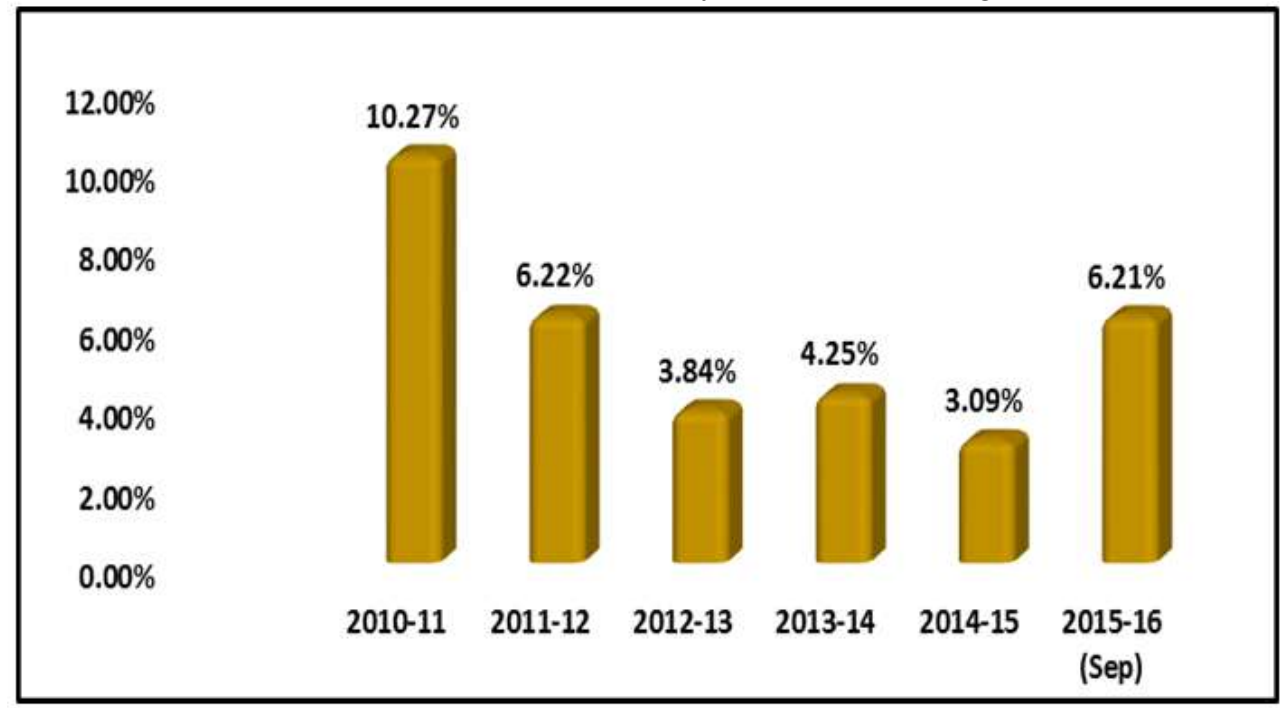

Chart 11: Collection Efficiency in Roads\& Bridges and Road Transport

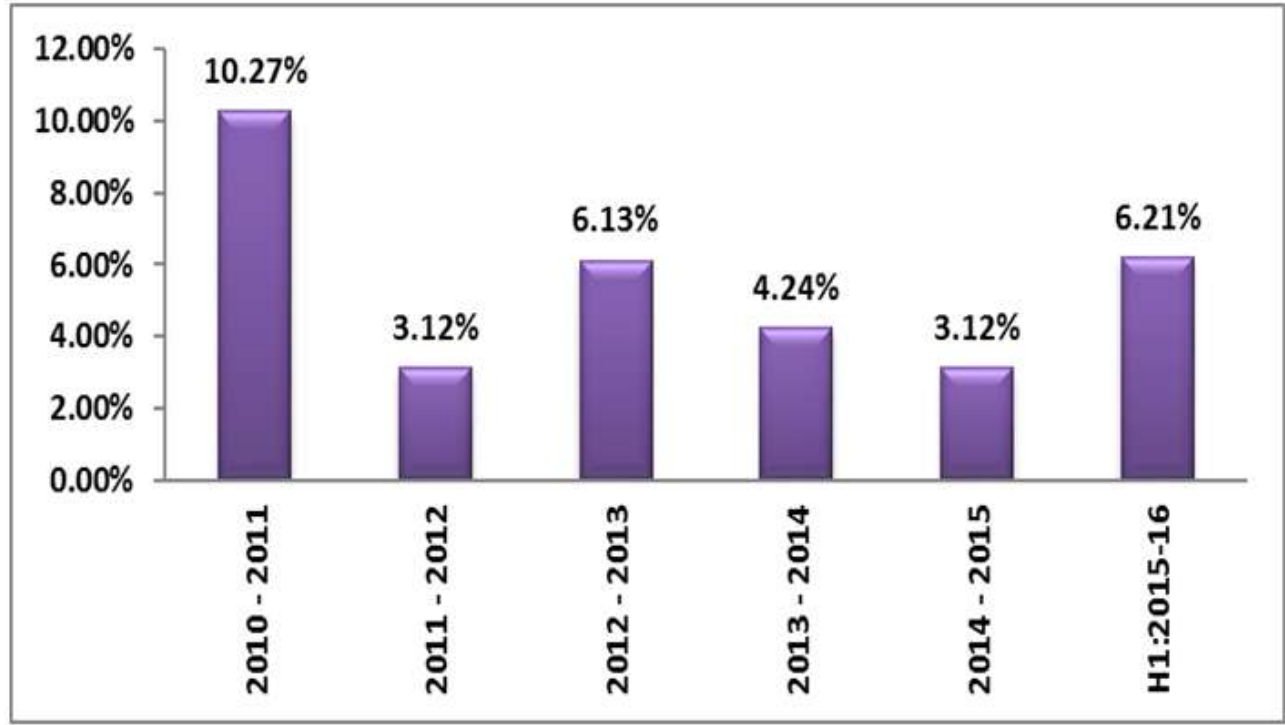

Chart 12: Collection Efficiency in Tourism in Odisha

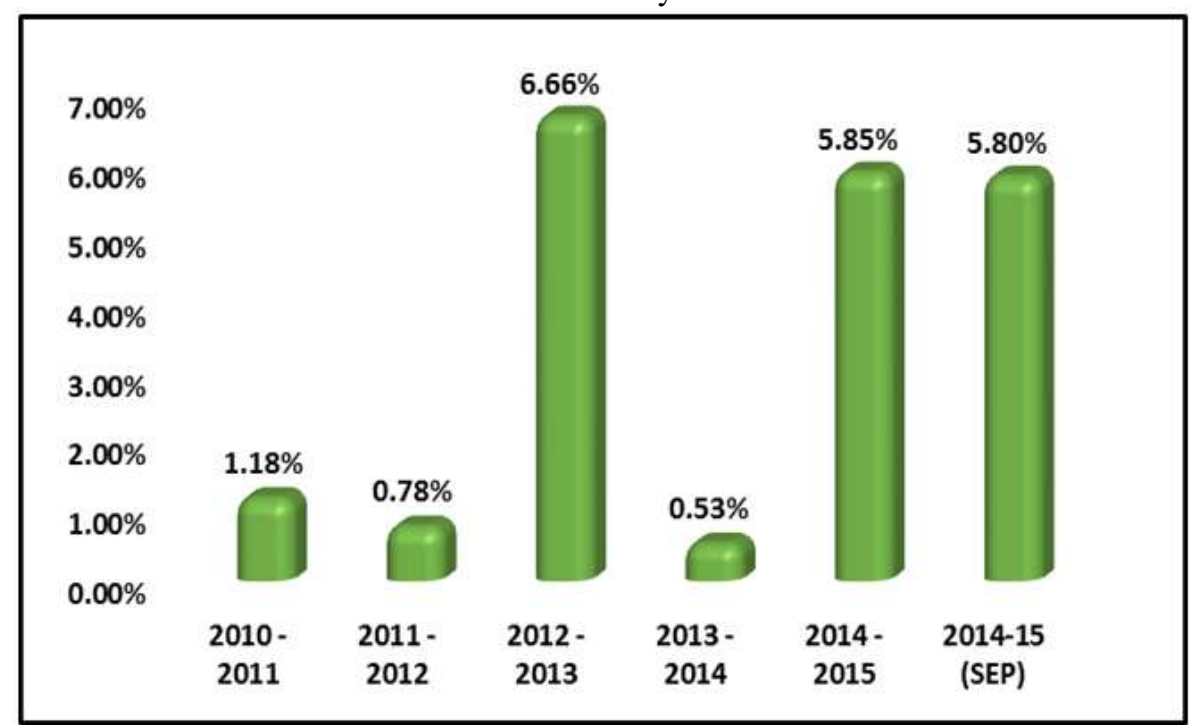


Chart 13: Collection Efficiency in Power Sector in Odisha

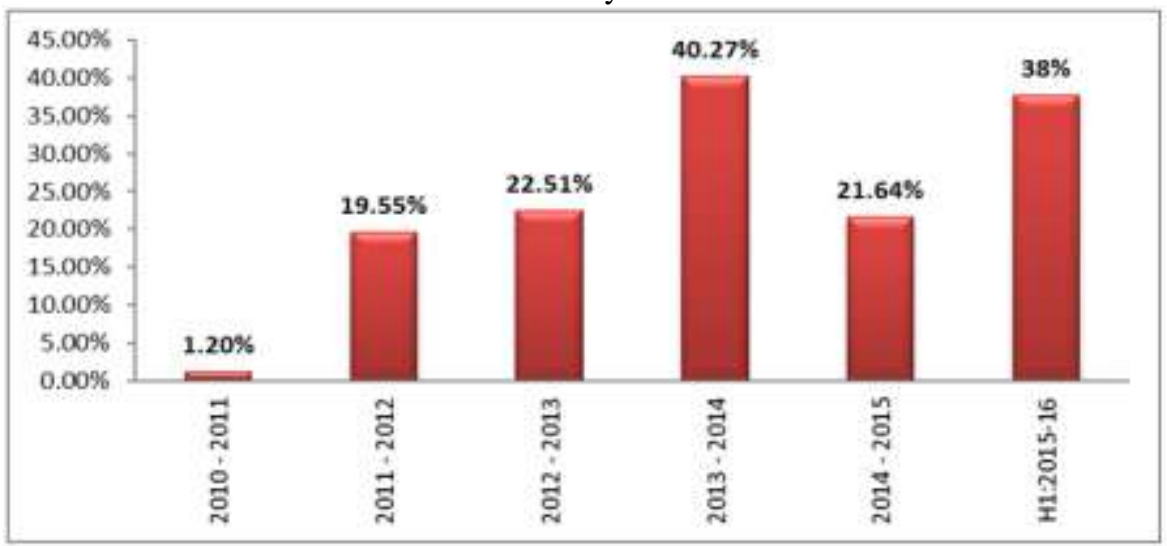

\section{Annexure II}

Pooled v/s Individual Effects

Panel data consisting of 15 Non-special category Indian sub- national governments for 5 years, from 2011-2015 has been exercised in the present study. The regression model can assume that there are time and individual sub- national government effects present, or these effects are absent in the data. A simple pooled regression would be appropriate, if these effects are missing, for finding parameter estimates. F test, which has null hypothesis that parameters obtained from pooling are more efficient than fixed effects model, has been performed for selecting between pooled and individual fixed effects. It presents the model selection between pooling regression and fixed effect model. The $\mathrm{F}$ test result for no fixed effects is presented in the following table.

Table 3: Test Statistics of Pooled versus Fixed Effects

\begin{tabular}{|l|l|l|l|l|}
\hline F test for No Fixed Effects \\
\hline \multirow{2}{*}{ Model } & Num DF & Den DF & F-Value & Pr> F \\
\cline { 2 - 5 } & 2 & 82 & 128.82 & 0.00 \\
\hline
\end{tabular}

In the present analysis, the $\mathrm{F}$ test supports fixed effect specification over the pooled regression specification.

\section{Fixed Effect v/s Random Effect}

After rejecting the pooled regression specification, the next step is to examine whether we should go for fixed effect or random effect model. The choice between fixed effect and random effect model has been carried out by performing the Hausman test in which the null hypothesis is that random effect estimators are more efficient than fixed effect model. The Hausman test form selecting between fixed effect and random effect model is depicted in the following table.

Table 4: Hausman Test for Random Effect

\begin{tabular}{|l|l|l|l|}
\hline \multicolumn{4}{|c|}{ Hausman Test Results } \\
\hline \multirow{2}{*}{ Model } & Chi2 value & Prob> Chi2 & Decision \\
\cline { 2 - 4 } & 25.03 & 0.00 & Go for Fixed Effect \\
\hline
\end{tabular}

The Hausman test results support the fixed effect approach for the above model. Thus, we performed fixed effect method to estimate the effect of per capita non-tax revenue in economic service sector on the per capita revenue expenditure in that sector.

Table 5: Regression Estimates Using Fixed Effect Method

\begin{tabular}{|l|l|l|}
\hline \multicolumn{3}{|l|}{ Dependent Variable: PRE } \\
\hline $\mathrm{R}^{2}=0.82$ & Coef. & Prob. \\
\hline Variables & $0.64 * * *$ & 0.00 \\
\hline PNTR & $0.77^{* * *}$ & 0.00 \\
\hline PCO & $1375.18^{* * *}$ & 0.00 \\
\hline C &
\end{tabular}

Note: $* * *$ denotes significance at $1 \%$ level 